\title{
PROPUESTA DE APLICACION COORDINADA DE EXPERIENCIAS NO CONVENCIONALES DE CONSTRUCCION DE VIVIENDAS A PROGRAMAS OFICIALES
}

\author{
(PROPOSAL FOR THE COORDINATED APPLICATION OF NON-CONVENTIONAL \\ HOUSE-BUILDING EXPERIMENTS TO OFFICIAL PROGRAMMES)
}

\author{
Aurelio Ferrero, Rocco Ortecho y Héctor Aníbal Uboldi, Arquitectos \\ ARGENTINA/PERU/URUGUAY
}

\section{RESUMEN}

Queremos despojar al trabajo que hemos presentado de toda voluntad de novedad: la forma progresiva de habitar no es una propuesta nueva; es, como hemos dicho antes, tan antigua como la vivienda misma, como la historia misma del hombre y su relación con el cobijo. Nuestra voluntad de aporte está en poner en valor esta modalidad, potenciándola; llevarla de su estadio informal y periférico a una alternativa apoyada desde todas las disciplinas.

En relación a este tema comprobamos, diariamente, dos realidades enfrentadas: los pueblos construyen mayoritariamente en forma progresiva; los gobiernos ignoran ese modo de construir cada vez que invierten en vivienda. El propósito de los autores es transformar esa realidad de choque en que las fuerzas actuantes se restan, en un encuentro donde los elementos que intervienen se sumen. Si la vivienda progresiva, sin apoyo ni respeto, cuestionada e interferida, es la forma de construir predominante, es indudable que si contara con el aval de los poderes públicos y con inversión adecuada, constituiría una alternativa de primera importancia entre las soluciones al problema de vivienda en Iberoamérica.

\section{SUMMARY}

It is our desire to divest the work we have presented of all claims to novelty: the progressive form of habitation is not $a$ new proposition; it is, as we have said before, as old as housing itself, as the very history of man and his relationship with shelter. Our desire to contribute lies in placing more importance on this modality, increasing its possibilities; taking it from its informal and peripheral state to an alternative receiving support from all disciplines.

Regarding this subject, two conflicting realities can be seen every day: people build mainly in a progressive way; goverments take no notice of that method of building whenever they invest in housing. The authors aim to transform that clashing reality in which acting forces are subtracted into a point of convergence in which the intervening elements are added together. If progressive housing, which is without support or respect, questioned and interfered with, constitutes the predominant form of construction, it cannot be doubted that if it were guaranteed by public authorities and received adequate investment, it would provide an alternative of the utmost importance among the solutions to the problem of housing in Latin America.
"Ursula se dio cuenta de pronto que la casa se habia llenado de gente, que sus hijos estaban a punto de casarse y tener hijos, y se verian obligados a dispensarse por falta de espacio. Entonces sacó el dinero acumulado en largos años de dura labor, adquirió compromisos con sus clientes, y emprendió la ampliación de la casa. Dispuso que se construyera una sala formal para las visitas, otra más cómoda y fresca para el uso diario, un comedor para una mesa de doce puestos donde se sentara la familia con todos sus invitados; nueve dormitorios con ventanas hacia el patio y un largo corredor protegido del resplandor del mediodia por un jardin de rosas, con un pasamanos para poner macetas de helechos y tiestos de begonias. Dispuso ensanchar la cocina para construir dos hornos, destruir el viejo granero donde Pilar Ternera le leyó el porvenir a José Arcadio, y construir otro dos veces más grande para que nunca faltaran los alimentos en la casa. Dispuso construir en el patio, a la sombra del castaño, un baño para las mujeres y otro para los hombres, y al fondo una caballeriza grande, un gallinero alambrado, un establo de ordeña y una pajarera abierta a los cuatro vientos para que se instalaran a su gusto los pájaros sin rumbo. Seguida por docenas de albañiles y carpinteros, como si hubiera contraido la fiebre alucinante de su esposo, Ursula ordenaba la posición de la luz y la conducta del calor, y repartía el espacio sin el menor sentido de sus limites". "En aquella incomodidad, respirando cal viva y melaza de alquitrán, nadie entendió muy bien cómo fue surgiendo de las entrañas de la tierra no sólo la casa más grande que habria nunca en el pueblo, sino la más hospitalaria y fresca que hubo jamás en el ámbito de la ciénagan.

Gabriel Garcia Márquez "Cien años de soledad" 


\section{EL PROBLEMA GENERAL}

\subsection{La razón de quienes reclaman el techo}

Toda propuesta (técnica, política, económica) necesita un encuadre ético, moral, filosófico, que la respalde y la haga comprensible. Dos planteos técnicos idénticos en sus detalles, por ejemplo, sustentados en distintos principios, pueden tener consecuencias muy diferentes. Es por ello que creemos necesario introducir un breve concepto sobre el contenido filosófico de esta propuesta.

Las plataformas políticas de los partidos mayoritarios del área coinciden en proponer cuatro temas como los que necesitan una atención preferente: educación, salud, trabajo y vivienda. Este equipo estudió y debatió sobre el modo en que cada uno de ellos fue evolucionando en el proceso histórico de la región; hemos comprobado que en los tres primeros (educación, salud y trabajo) es en los que más se ha avanzado legislativamente, y en los tres, la libertad irrestricta ha sido regulada y contenida para dejar una parte de su espacio (cada vez más amplio) al concepto de justicia.

La enseñanza se convirtió poco a poco en una actividad predominantemente pública $y$, aun la privada que todavia coexiste con la oficial, está sometida a numerosos controles, regulación de programas, etc. La relación enseñar-aprender ya no es una relación comercial contractual entre un agente que vende un servicio y otro que $10 \mathrm{com}$ pra, sino que, mediante el instituto de la gratuidad ofrece "igualdad de posibilidades", al menos teórica, a todos (concepto de justicia). Pero la sociedad, a través del estado, no sólo controla sino que además obliga. Hoy no existe la libertad de aprender o no aprender, de educarse o no educarse, sino que se ha sancionado la obligatoriedad de concurrir a la escuela e incluso, en muchos paises, a las aulas secundarias.

La salud y el trabajo recorren un camino parecido. En ambas actividades el estado legisla y reglamenta permanentemente, estableciendo controles, recaudando fondos compulsivamente (tasas, impuestos, retenciones, aportes, etc.) para proceder a su posterior redistribución, basado en razones de interés general: financiación de hospitales, dispensarios, institutos de rehabilitación, etc. en el caso de la salud; pago de jubilaciones, pensiones, etcétera, en el caso del trabajo. En las dos áreas, también se van restringiendo ciertas libertades, mediante la obligatoriedad de cumplir una serie de deberes que ya no están en la libre elección de cada uno: exigencia de exámenes preventivos para numerosas gestiones, vacunaciones, controles sanitarios sobre la comercialización de alimentos, retiro de la actividad laboral a cierta edad, etc.

De esta manera se avanza paulatinamente en una búsqueda de cierto equilibrio social:
- los que saben (pagados por la sociedad) enseñan a los que no saben (que obtienen el servicio en forma gratuita),

- los que están sanos (que aportan los fondos) pagan la atención de los enfermos (que reciben atención sin cargo),

- los que están en actividad (que realizan los aportes jubilatorios) cubren el descanso de los que ya se han retirado (que continúan recibiendo una remuneración).

El tema de la vivienda, el cuarto de los priorizados por los partidos políticos, y en el que debe centrarse este trabajo, no puede ser ajeno a esta filosofia. Es, sin embargo, en el que menos se ha avanzado: la vivienda, aun con intervención del Estado, sigue siendo fundamentalmente un producto de mercado.

Entendemos que deben acelerarse las modificaciones necesarias para que este campo se incorpore de un modo más enérgico al camino analizado, a partir del concepto, coherente con los anteriores, de que quienes ya han obtenido su techo deben contribuir a que lo consigan quienes aún no lo tienen.

\subsection{Los componentes de la ecuación}

Los dos términos de la ecuación planteada (obviamente viviendas y recursos) pueden analizarse desde dos aspectos: cuantitativo y cualitativo.

En el aspecto cuantitativo, el concepto común que los define es la "escasez".

En el aspecto cualitativo, cada uno de los términos se caracteriza por un problema que agrava la situación compartida de escasez:

- en el caso de las unidades de vivienda existentes, a la situación de escasez es necesario agregarle el concepto de ineptitud (precariedad, obsolescencia, superfecie reducida que conduce al hacinamiento y la promiscuidad). Esta presencia de viviendas ineptas en el parque existente, reduce la cifra útil de éste, aumentando la escasez,

- en el caso de los recursos disponibles en la región, a la situación de escasez es necesario agregarle el concepto de mala distribución de esos recursos, que disminuye la eficacia de los mismos.

Hemos elegido como tema central de este trabajo el término de la ecuación definido por los recursos (Fig. 1). 


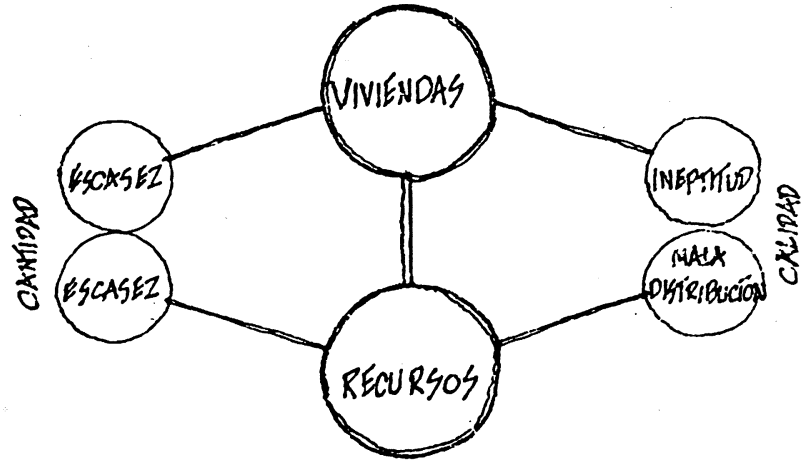

Fig. 1.-Los componentes de la ecuación.

\subsection{El manejo de los recursos}

La región soporta una crisis económica de carácter crónico, cuyos datos más contundentes son el endeudamiento externo, la dependencia y la pobreza creciente. Mientras el continente no construya su independencia económica, no encontrará los recursos necesarios para construir las viviendas que necesita.

A este panorama de escasez se suma, como ya adelantamos, un cuadro de inadecuada distribución de los recursos.

Para ordenar un análisis, pensaremos en tres aspectos de los recursos: obtención, distribución, recuperación. Mencionaremos la obtención y la recuperación, pero haremos eje en la consideración de la distribución.

Obtención de los recursos. Vimos que la palabra clave es "escasez": para superarla es necesario el aumento de la inversión en vivienda, pero ello sólo es posible en un marco de expansión económica que genere mayores recursos. Esta generación es, en todos los casos, una variable lenta; por otra parte escapa al campo de los planificadores en vivienda (ámbito de los autores) para entrar en el campo de la planificación global y sobre todo económica. De todos modos, anotaremos algunas consideraciones marginales sobre el tema, coherentes con la filosofía de este trabajo, planteada en las páginas introductorias.

La principal recaudación destinada a vivienda en el continente, procede de fondos retenidos (a porcentaje fijo) de los sueldos. No creemos que sea el mejor procedimiento. Si los fondos debieran proceder de los sueldos, no es justo gravar a todos en igual medida, sino aplicar una escala en que los porcentajes de aporte aumenten cuando aumenta la categoría del sueldo, contribuyendo a una redistribución de los ingresos. Proponemos sustituir o complementar esta recaudación con la aplicación del concepto presentado en la introduc- ción ("quienes ya han obtenido su techo deben contribuir a que lo consigan quienes aún no lo tienen"): los miembros de la sociedad que ya tienen vivienda, que por otra parte no cargan en su presupuesto con el costo del alquiler, deben contribuir con un impuesto directo, cuyo valor tendrá una relación creciente con la superficie poseida.

Distribución de los recursos. Frente a la lentitud de generar recursos, la distribución de los ya existentes es una variable rápida (dependiente de una decisión política). No es una medida suficiente, pero contribuiría a que la solución obtenible sólo mediante un aumento de la inversión, pueda irse construyendo desde ya, con los recursos existentes. Este es el centro de nuestra propuesta, que utiliza como modelo de trabajo el ejemplo argentino.

Su desarrollo se basa en una metodologia de trabajo para orientar una distribución de los recursos más racional y equitativa que la actual y en una alternativa para la construcción de viviendas distinta de los planes convencionales.

Recuperación de los recursos. El Estado, como constructor de viviendas, no las regala. Su deber es recuperar la inversión para dar continuidad al mecanismo (nota 1), atendiendo la necesidad dinámica de construir permanentemente más viviendas (crecimiento vegetativo, reposición, etc.). Esta necesidad de recuperación implica un reintegro mensual de los adjudicatarios, cuyo costo es mayor cuanto más alto es el costo de la unidad recibida. La actual realidad indica que quienes pueden comprometer ese reintegro mensual están en las categorias de menor necesidad.

Resulta asi un circuito irracional, en el que los sueldos bajos aportan al fondo correspondiente para que reciban vivienda los sueldos altos, generando una redistribución al revés de los ingresos. Pero la realidad concreta es aún más grave. Como consecuencia de la inflación crónica, y pese a las previsiones tomadas por las autoridades respectivas en relación a la actualización de las cuotas que deben reintegrar los adjudicatarios de vivienda, éstas siempre terminaron muy por debajo de su valor real resultando, en la práctica, subsidiadas. De tal modo, los bajos sueldos de los pobres sin techo, cuya capacidad de reintegro nunca es suficiente, terminan subsidiando los planes de vivienda para las capas medias.

Nuestro trabajo propone una política de vivienda con variedad de alternativas constructivas y financieras, de modo que haya espacio para la incorporación a algún tipo de solución de todas las situaciones.

Nota 1.-Los autores reconocen la existencia de situaciones especiales (no muy numerosas en el caso argentino pero de gran importancia en otros paises iberoamericanos), cuya capacidad de reintegro es prácticamente nula, para quienes la única alternativa válida es alguna forma de subsidio (total o parcial). 


\subsection{Una propuesta metodológica}

La tendencia habitual en los planes de vivienda oficiales es la construcción de grandes conjuntos habitacionales de unidades terminadas. Son células de distinto tamaño que contemplan necesidades diferentes a través del número variable de dormitorios, pero cada una de ellas completa en sí misma (diseño acabado o con alguna relativa posibilidad de crecimiento, niveles de terminación definitivos, instalaciones completas, etc.). Los patrones de diseño son los clásicos, provenientes de las oficinas de los organismos de vivienda y de los ambientes universitarios, respondiendo a los hábitos y preferencias de las capas medias, a la que pertenecen los funcionarios.

Sin embargo, si se relevaran las aspiraciones y las costumbres reales de la población a la que deberian llegar las viviendas construidas por el Estado, se comprobaría la inadecuación de tales propuestas.

A tal contradicción apunta el eje central de este trabajo, cuya propuesta es que la planificación de la construcción de viviendas por el poder público no surja de patrones congelados en oficinas de diseño y planificación, sino que tenga su punto de arranque en un diagnóstico de situación compuesto por:

- diagnóstico de necesidades

- diagnóstico de recursos

- diagnóstico de aspiraciones.

Diagnóstico de necesidades. Como deciamos al comienzo el problema de la vivienda surge de una variedad de situaciones, de una diversidad de casos, que de por si cuestionan toda solución única. Evaluar correctamente las necesidades es uno de los pasos indispensables para encontrar las soluciones correctas.

En Argentina, el déficit real está formado por una serie de categorias que difieren en su nivel de carencia. A modo de ejemplo enumeramos las más importantes:

a) situación de intemperie (carencia total);

b) villa de emergencia (ocupación extralegal de un sitio, propiedad de los materiales precarios con que se ha construido);

c) préstamo (en casa cedida temporariamente o en parte de una casa que se comparte con el dueño, frecuentemente suegros-padres de una pareja joven);

d) propietario irregular (sin documentación legal, loteo irregular, etc.);

e) propietario de un lote sin servicios; f) propietario de una casa sin lote (construyó con materiales propios en terreno prestado, al fondo de la casa de un pariente o amigo);

g) propietario de un lote baldio;

h) propietario de un lote con una pieza;

i) propietario de una casita sin terminar;

j) propietario de una casa obsoleta

k) inquilino.

Esta última categoria tiene un significado especial, ya que no hace al déficit cuantitativo, sino a una iregularidad del mercado, en cuanto no contempla el fin social de la vivienda sino que la convierté en un producto; sin embargo, la situación de inquilino con frecuencia se incorpora al déficit, ya que se superpone con alguna de las categorias de éste (arrendamiento de casitas sin terminar o de casas obsoletas, con frecuencia inquilinatos).

Si ubicamos las categorias señaladas (o las que correspondan en cada caso de acuerdo al área estudiada) en un sistema de coordenadas, y las ordenamos de mayor carencia a menor carencia, obtenemos una curva escalonada.

El paso siguiente es cuantificar los casos a incorporar en cada categoría de modo que puedan detectarse las categorias que por su mayor importancia cuantitativa merezcan una atención preferente.

Entre la curva resultante y la situación de satisfacción se ubica la magnitud del déficit. (Fig. 2).

Diagnóstico de recursos. A los efectos de la propuesta metodológica, lo consideramos un dato del problema (por ciento fijo del producto bruto inter-

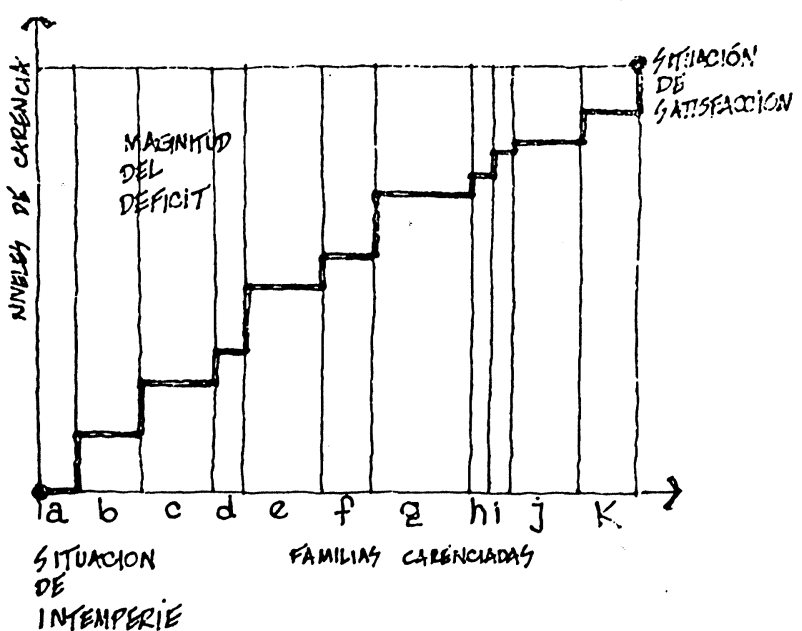

Fig. 2.-Diagnóstico de necesidades. 


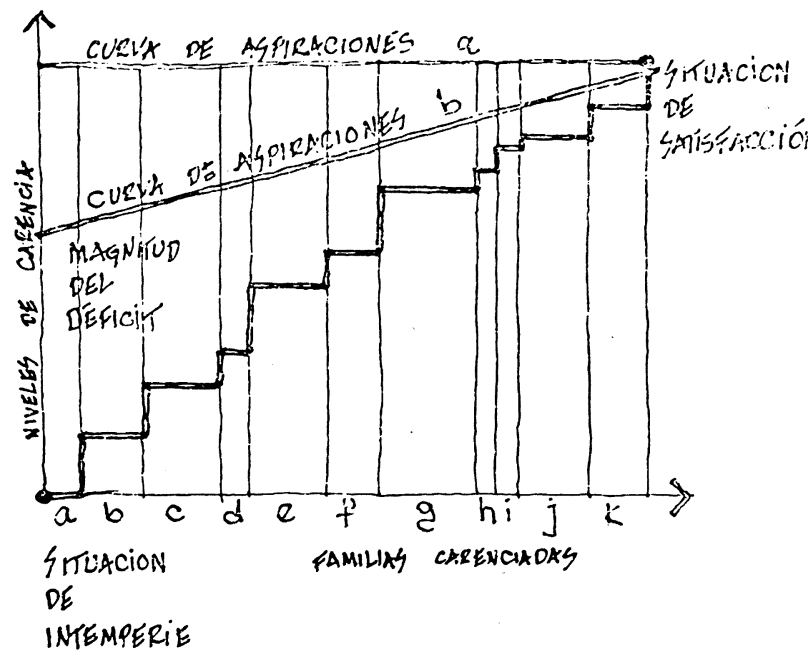

Fig. 3.-Curva de aspiraciones.

no, cifra establecida en el presupuesto, etc.). Ya hemos expresado en el capitulo anterior una serie de análisis sobre su obtención, distribución y recuperación, tema que retomaremos al final de este trabajo.

Diagnóstico de aspiraciones. Al iniciar este punto 1.4. hablábamos de un tercer diagnóstico necesario: el diagnóstico de aspiraciones. Los dos anteriores (necesidades y recursos), son habitualmente manejados por las autoridades; no asi el tercero, que entendemos tan importante como los anteriores y es uno de los fundamentos de nuestra propuesta.

Las autoridades parten de una ubicación de la curva de aspiraciones (a) coincidente con el nivel de satisfacción (vivienda de superficie adecuada, con instalaciones completas y todos los items terminados). Esto resulta en un costo $\mathbf{A}$ para cada unidad de vivienda. Pero este nivel de aspiraciones a, proveniente de funcionarios de las capas medias y técnicos universitarios, correcto quizás en teoria, no coincide con las aspiraciones reales y concretas de los que no tienen techo. El estudio de estas aspiraciones es imprescindible para ajustar las políticas oficiales y acercarlas a un nivel de realidad. (Fig. 3).

Los autores, luego de observar en sus respectivos paises los procesos de obtención de viviendas de los pobres, han reunido sus experiencias en este trabajo $y$, con las diferencias de cada caso, que no hacen a la esencia del asunto, han comprobado que la gente no espera a tener su casa terminada para habitarla. Para la gran mayoria, lo importante es liberarse de la inseguridad del alquiler o de situaciones más precarias aún, mediante la conquista de un primer escalón de vivienda que, una vez habitado, crece y se completa. Parece justo entonces, analizar si no es necesario tener en cuenta este diagnóstico de aspiraciones y construir de otra manera.
En trabajo realizado por el Centro Experimental de la Vivienda Económica en 1982, en Córdoba, un muestreo realizado en la ciudad, tomando como base las cuatro zonas homogéneas de menor nivel (físico, funcional, socio-económico) de las en que está dividida la ciudad, se obtuvieron algunos datos muy contundentes. El $81,0 \%$ del universo muestreado es propietario de su vivienda y entre ellos, el $78,4 \%$ la construyeron por propia iniciativa.

La antigüedad de comienzo de dichas construcciones era de 17,3 años y estaban ocupadas desde hacia 16,0 años, con un tiempo promedio entre comienzo y ocupación de 1,3 años, tiempo necesario para construir el minimo habitable requerido por sus aspiraciones. En el momento de la investigación, 16,0 años después de vivir en ellas, el $57,5 \%$ de las casas continuaba sin terminar. El $85 \%$ construyó en etapas. Esto no es sinónimo de estancamiento, sino de un progresivo crecimiento que, probablemente, fue acompanando el crecimiento familiar (tanto cuantitativo como económico); esto queda probado por el hecho de que el tamaño predominante de la vivienda en el momento de habitarla era de un solo ambiente $(47,4 \%$ de los casos) y en el momento del relevamiento dicho tamaño habia crecido a 4 ambientes $(50,0 \%$ de los casos). El $80,0 \%$ de los entrevistados demostró su voluntad de insistir en el mismo sistema de producción, por si mismos, poco a poco, aunque casi todos expresaron también la importancia de una financiación de ese proceso $(77,5 \%)$. De los componentes que conforman una vivienda, sólo cuatro estaban terminados en el momento de habitar la casa (cimientos, capa aisladora, paredes y techo); los demás admitian distintos grados de terminación, siendo los más incompletos cubierta, pintura, cerramientos y pisos.

Datos extraídos de "Estructura de costos en la construcción de viviendas: vivienda autopromovidan. Autor CEVE. Publicación Subsecretaria de Ciencia y Tecnologia.

Una curva de aspiraciones real (b), basada en la consulta y en la realidad de los usuarios y no en patrones teóricos, no es una paralela al eje horizontal, sino una curva ascendente, en la cual las aspiraciones de los que más tienen es mayor que las de quienes están más carenciados. Su posición es inferior a la curva a, de modo que la magnitud global del déficit puede reducirse considerablemente y los recursos disponibles pueden acercarse un poco más a satisfacer las necesidades relevadas (Nota 2).

Pero esta no es la conclusión fundamental; lo importante es comprobar que es necesario ofrecer distintos niveles de vivienda, compatibilizando aspiraciones con capacidad de pago de los usuarios. De otro modo se llega a un producto que, si bien puede ser impecable, es inaccesible.

\subsection{Los planes de vivienda}

Dos líneas básicas de intervención se abren a las autoridades públicas:

- recuperación de viviendas deterioradas, completamiento de viviendas sin terminar, crecimiento de viviendas insuficientes;

- planes de vivienda nuevos.

Nota 2.-Aclaramos que este razonamiento no procura minimizar la magnitud del déficit, sino fundamentar la necesidad de ofrecer alternativas más modestas, más en consonancia con las aspiraciones reales de los más pobres. 
La primera, refleja la situación de un gran número de casos (barrios periféricos casi en su totalidad, zonas céntricas deprimidas, etc.). El grupo de mayor interés es el que se relaciona con los barrios periféricos, donde la mayoria absoluta de las casas están sin terminar, tienen instalaciones parciales, son de tamaño insuficiente, e incluso contienen problemas técnicos serios. Existen sin embargo una multitud de unidades (hoy incorporadas al déficit) que, con inversiones reducidas, pueden alcanzar niveles más satisfactorios. La planificación oficial debería contemplar estas situaciones mediante apoyo financiero y asistencia técnica adecuada.

Aplicar recursos a este sector es conveniente para el Estado, porque permitiria incorporar al parque útil una cantidad importante de unidades, con una menor inversión por unidad. Es de interés además, porque contribuiria grandemente a mejorar la imagen urbana deteriorada de dichos barrios y porque estimularía una mayor inversión en vivienda, proveniente del aporte propio de los usuarios.

La segunda línea es indudablemente la de mayor impacto en el déficit y la de mejores posibilidades de planificación. El manejo habitual ha conducido a planes de vivienda terminada (convencionales); nuestra propuesta es incorporar planes de vivienda incompleta (progresiva).

Existen razones válidas (concentración urbana, costo de infraestructura, experiencia acumulada, capacidad instalada, etc.) para realizar planes de vivienda en bloques. Lo que no es lógico es que sea esa la única forma de construir viviendas oficiales, o la absolutamente predominante.

Una atención a la curva de aspiraciones b tiene variados fundamentos:

a) permite distribuir los recursos más horizontalmente, construyendo mayor cantidad de unidades;

b) no es lógico que los países pobres (a cuya categoria pertenecen los de la región) copien recetas de los paises ricos. La vivienda terminada universal es un lujo incompatible con la gran cantidad de unidades que se necesitan y una fantasia inalcanzable en relación a los recursos con los que se cuenta;

c) el nivel de aspiraciones de los que están dentro del déficit es lógico que sea decidido por ellos mismos y no por las autoridades que generalmente pertenecen a otro sector socioeconómico, con aspiraciones más altas;

d) la mayor parte de la gente que tiene problemas de vivienda aspira a mucho menos de lo que las autoridades proponen en sus planes.

\section{LA VIVIENDA PROGRESIVA}

Pensamos en la vivienda progresiva no sólo como una alternativa marginal que responde a una coyuntura de crisis, sino como una variable válida en todo momento en toda política habitacional.

La vivienda progresiva no es necesariamente un concepto peyorativo de la vivienda, antes bien, y si los recursos económicos fueran abundantes en lugar de escasos, con igual o mayor razón debería ser el concepto más válido. La vivienda de los hombres es un producto que se incorpora a la cultura más cerca de la naturaleza que de la industria. El producto industrial nace como cosa acabada; su nacimiento marca el ápice de su valor y de su servicio útil. La naturaleza en cambio es una constante evolutiva, parábola de nacimiento, crecimiento, vértice, decrecimiento y muerte. El concepto óptimo de vivienda debiera concebirla dentro de este proceso evolutivo; no debiera nacer en el vértice para marchar hacia su muerte, sino iniciarse en un camino de crecimiento que comparta y acompañe el proceso de crecimiento humano y familiar de sus habitantes.

En términos de poesia, podríamos decir que la vivienda debería nacer como un núcleo capaz de proteger de la intemperie al germen de la familia, crecer en tamaño y en valores junto a ésta, llegar al vértice al mismo tiempo, para iniciar luego un maduro proceso de involución de su ciclo vital. (No en vano la vida útil de una vivienda normal puede asimilarse a la vida útil de la especie humana). En una ecuación de abundancia, por otra parte, no habria razones para dar a una vivienda una vida mayor que la de sus hacedores $\mathrm{ni}$, por supuesto, para que su deterioro los precediera. (Aunque resultara más cara).

Es otro el punto de partida de esta propuesta, porque estamos en una economia de escasez. $Y$ en situación de escasez conviene hablar en términos de tecnología. Sucede entonces que con distintos fundamentos, distintas técnicas y distintos diseños, el concepto de vivienda evolutiva surge también el más apropiado para este momento en esta región.

\subsection{Orígenes y posibilidades de su diseño}

Para encontrarnos con los fundamentos del diseño de la vivienda progresiva no es necesario rastrear ejemplos aislados en el pasado ni formular una nueva teoria de diseño hacia el futuro. La vivienda en nuestros paises ha tenido tradicionalmente un carácter progresivo (tanto la vivienda rural o natural como la vivienda urbana del gringo inmigrante). Surge muy clara, en ambos casos, la necesidad del habitante y transformación de su vivienda (Esquemas A).

En ambos ejemplos, y estrechamente relacionadas con el diseño, existen claras manifestaciones de 
Esquemas A

TPPOLOSIX PREDOMINAMEE VIVIENDA RURAL

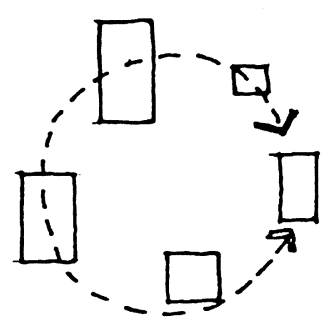

ESOUEMT TOHNUCLEAR ALREDEDOR DEL PATIO

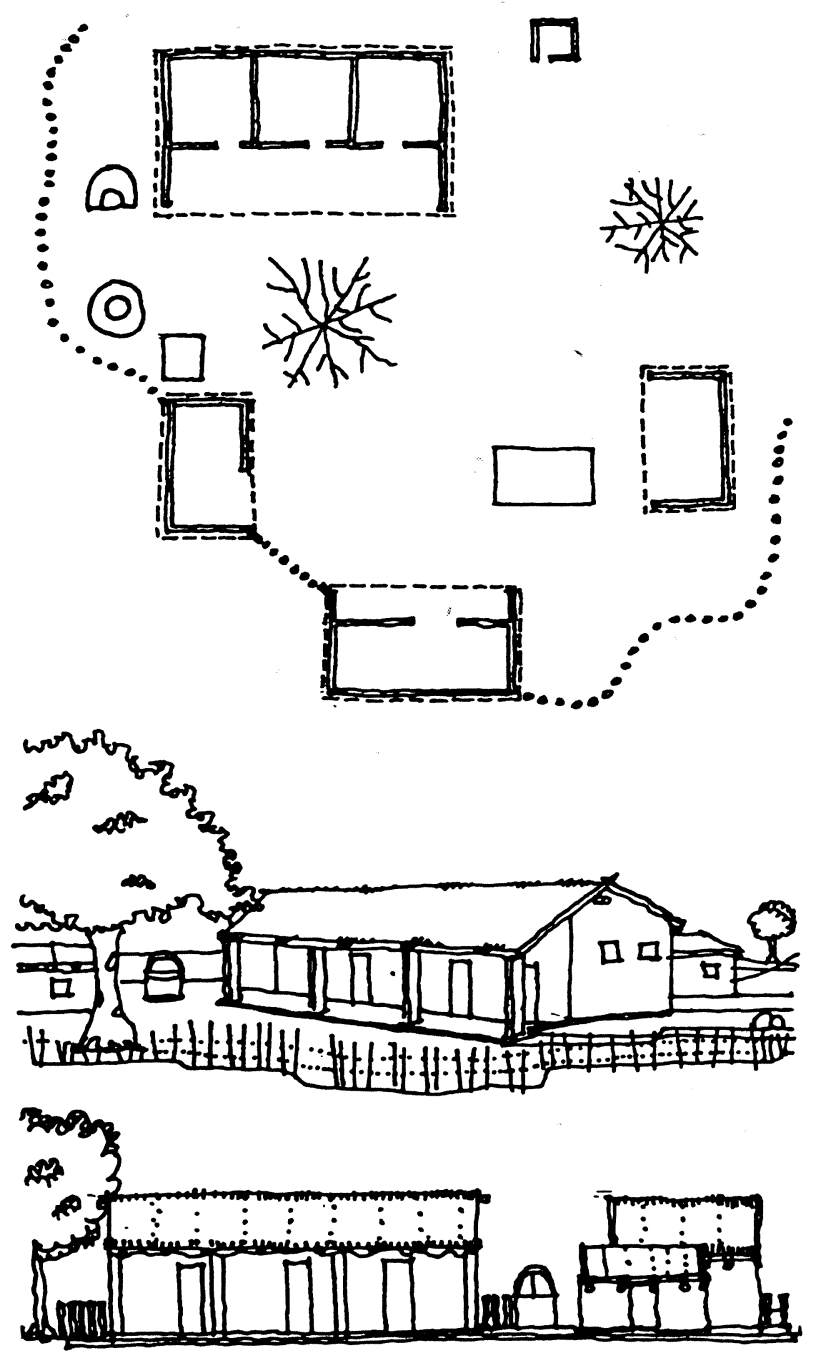

un avance tecnológico también progresivo, cuyo ejemplo más ilustrativo puede ser el desarrollo de la columna, desde su origen como horcón hasta su actual desarrollo (Esquema B).

Este proceso paulatino sufrió un corte en un momento dado, pero no por iniciativas y voluntad de los constructores autóctonos sino por una fuerte presión externa (producto fundamentalmente de la industrialización y su necesidad de conquistar
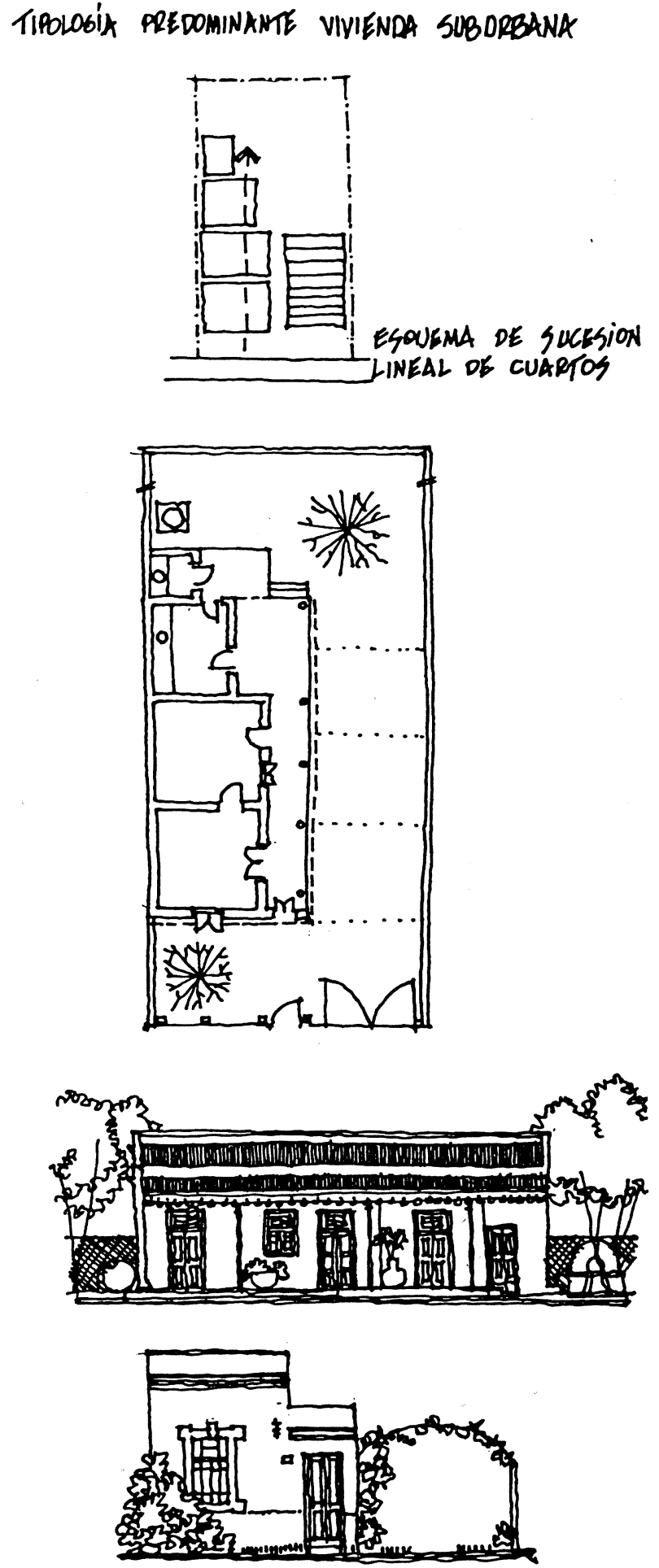

mercados). Este corte dado en los componentes tecnológicos de la vivienda tradicional se repitió en la vivienda misma como totalidad, mediante la importación de modelos de vivienda terminada: traídos al pais en circunstancias económicas de auge, introdujeron modelos individuales como el "chalet" californiano o ambiciosos planes de vivienda terminada agrupada, inspirados en el mismo modelo, con equipamientos e infraestructura completos. Con el tiempo, las condiciones econó- 


\section{Esquema B}
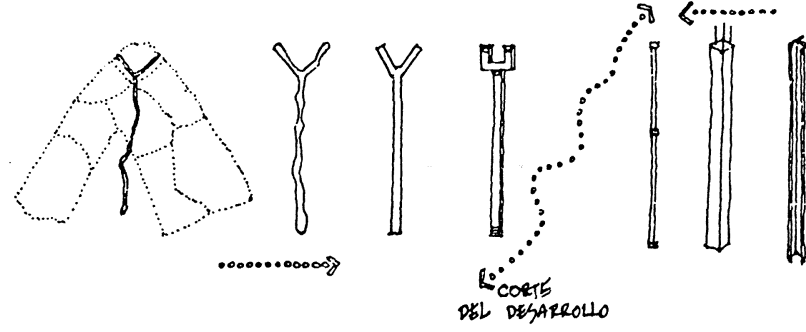

micas se deterioraron, pero la persistencia de aquellos modelos no dio paso a nuevos planos, sino que se plasmó, acorde con nuevas situaciones de menor bonanza, en planes degradados.

Los técnicos hemos colaborado en este camino, insistiendo en proyectos puristas relacionados con teorías de diseño intelectualizadas, basados en propias aspiraciones $y$ en términos de proyecto final, sin contacto con los problemas reales y cotidianos de los usuarios. Para ello, bastaría repasar las condiciones en las cuales se desarrollan las viviendas en nuestros barrios populares, tratando de comprender en profundidad las dificultades reales que encuentran sus habitantes. No es extraño para nosotros llegar a viviendas en que el recibo son unos cimientos con unos cuantos ladrillos apilados en espera de una mejora económica para hacer aparecer la otra pieza, modalidad que los usuarios han comenzado a manejar cada vez mejor.

Este mismo proceso evolutivo sucede en las villas de emergencia (villas miseria, barriadas, cantegriles), donde a las dificultades de construcción se agrega la ocupación extralegal de tierras fiscales, generando un problema suplementario.

Es necesario buscar alternativas: diseños pensados para un completamiento paulatino y no diseños rígidos; diseños que permitan la libre participación del usuario en la transformación de su unidad, sin los riesgos habituales de alterarlos y degradarlos.

\subsection{Aspectos tecnológicos propios}

La tecnología, como el diseño, deben ser coherentes con el producido al cual desean aplicarse. En nuestro caso, asi como no es posible pensar en sofisticados diseños de fundamentación únicamente estética, sin contradecir la idea de sencillez y humildad inherente a la vivienda de los pobres, tampoco es posible pensar en tecnologias complicadas y orgullosas, contradictorias con la región en que tienen que aplicarse y con los hombres a quienes se dirige. La tecnología desarrollada en cada región debe ser espejante de sus recursos, de sus necesidades, de sus ambiciones, de su cultura en definitiva.
Si las tecnologias "pesadas" o "modernas" resultan impensables para los modos de construir más aptos en nuestra realidad, es conveniente también advertir frente a las tecnología "adecuadas" o "intermedias", cuando éstas no son un producto auténtico del lugar y del hombre que la utiliza. La crisis del hiperdesarrollo ha generado una búsqueda del regreso a la sencillez, a lo natural y primitivo. Pero esta búsqueda, cuando se genera desde la riqueza y la abundancia, corre el riesgo de no ser auténtica, de ser una frivolidad más y un nuevo producto de exportación. Lo válido es que los propios paises subdesarrollados sean los dueños de una política de selección, creación y combinación de todas las tecnologias, en función de sus verdaderas necesidades. Los problemas propios de la pobreza y el subdesarrollo son una disciplina en la cual sólo pueden ser especialistas los mismos habitantes de la pobreza y el subdesarrollo.

Debemos agregar que las soluciones deben plantearse con el concurso de la comunidad, mediante medios pertinentes de participación auténtica. Los grupos humanos tienen, respecto a sus problemas habitacionales, preferencias y estilos. Cualquier política tenderá al fracaso si no está basada en lo que los mismos usuarios establecen como su necesidad, ya que es esto lo que ellos estarán dispuestos a defender. Si no es fácil encontrar estos medios de participación, hay que ensayarlos hasta dar con ellos.

No existe una solución al problema de la vivienda en Iberoamérica, singular y única, desde el punto de vista tecnológico. Sólo una pluralidad de acciones, atendiendo la diversidad de casos presentes, garantizan una correcta intervención. Desde el mejoramiento del hábitat deficitario existente, llevándolo a niveles aceptables, hasta la construcción masiva de bloques de vivienda, las alternativas son variadas y todas deben estudiarse.

En sintesis, entre los aspectos generales del problema tecnológico señalamos:

a) el aprovechamiento racional de los recursos regionales;

b) la incorporación del concepto de progresividad también en las soluciones tecnológicas;

c) la coordinación modular que permita máxima combinabilidad de insumos y productos;

d) la participación de los destinatarios en las decisiones.

\subsection{Su organización independiente}

No es posible pensar en una política seria y masiva de vivienda progresiva, considerando solamente aspectos de diseño y de tecnología; la concreción de tales planes (organización, financiamiento, et- 
cétera) no puede basarse en formas que pertenecen a otras operatorias. La vivienda progresiva exige la experimentación y puesta a punto de mecanismos organizativos nuevos, sin perjuicios ni condicionamientos previos, sean impuestos por la autoridad política o estén implicitos en los mismos planificadores. Debe crearse un instituto especializado en el tema, dirigido e integrado por personas que aporten una mentalidad nueva para atacar el viejo problema de la vivienda para los más pobres. Los clásicos funcionarios de los institutos de vivienda tradicionales (ministerios, secretarias de estado, bancos hipotecarios. etc.) tienen demasiado arraigados en su trayectoria los conceptos convencionales y no serian capaces de producir, con la imaginación necesaria, los cambios que resultan imprescindibles. No es un departamento especializado de un banco hipotecario el que puede conducir esta nueva modalidad de intervención, sino un instituto creado especialmente para tal fin, con una acción totalmente orientada hacia ese objetivo. Es en este instituto donde podrán encontrar un sitio propio y desarrollarse ideas como la financiación no convencional, el banco de tierras, el banco de materiales, la cooperativa de servicios profesionales y otras que surgirán de la acción, como resultado de ésta.

Banco de tierras. El primer escalón de la vivienda es previo a la vivienda misma: es la tierra. En mercados donde predomina la especulación inmobiliaria es necesario que el Estado asuma una responsabilidad primaria en la comercialización de la tierra, creando su propio banco de tierras, con capacidad de intervención en la regulación de dicho mercado.

Banco de materiales. La segunda instancia de la vivienda progresiva en los casos, muy numerosos, de autogestión del usuario, son los materiales. Obtenida la tierra, surgen las dificultades de ob- tención de los materiales necesarios para concretar el techo buscado. Un banco que asegure el financiamiento de paquetes de materiales, unido al asesoramiento para su uso, es un complemento eficaz para este tipo de operatoria.

Servicios profesionales. Cuando se obtiene la tierra y el crédito para los materiales, surge la necesidad de la asistencia técnica. En una política integral relacionada con la vivienda progresiva, debe procurarse la formación de alguna figura de servicio profesional distinta del actual ejercicio liberal, que haga accesible el asesoramiento técnico necesario a quienes procuran salir de su problema de vivienda. Coordinar la formación universitaria con los centros profesionales y el instituto especializado correspondiente, facilitaría el ofrecimiento de un servicio integral.

Instituciones intermedias. El $80 \%$ de la población activa del pais forma parte de alguna institución intermedia (cooperativa, sindicato, mutual, etc.). Toda política de vivienda que procure la participación de los sectores beneficiados debe aprovechar las estructuras existentes entre el Estado y el usuario. De tal modo, es conveniente la formulación de programas habitacionales a través de estas estructuras, estimulándolas a integrarse a una red nacional, coordinada centralmente por el Estado.

\subsection{Algunos ejemplos}

Presentamos a continuación un cuadro que sintetiza las cuatro formas más frecuentes en los programas de vivienda progresiva. Luego desarrollaremos un ejemplo de cada una de ellas, con el propósito de mostrar que, tanto en diseño como en tecnología, el panorama es tan rico y original como se quiera desarrollar. 


\section{TIPOS DE VIVIENDA PROGRESIVA}

1. Por rehabilitación (mejoramiento del hábitat existente).

2. Por entrega de tierra inicial (sitio con servicios y traslado a fondo de lote en vivienda provisoria).

3. Por completamiento de vivienda cáscara (cerramientos verticales, mejoramiento de estructura básica).

4. Por anexado de superficie cubierta (ampliación de áreas terminadas).

\section{1. adosada (vivienda mononuclear)}

4.2. agregada (vivienda polinuclear)

4.3. adosada en planta alta
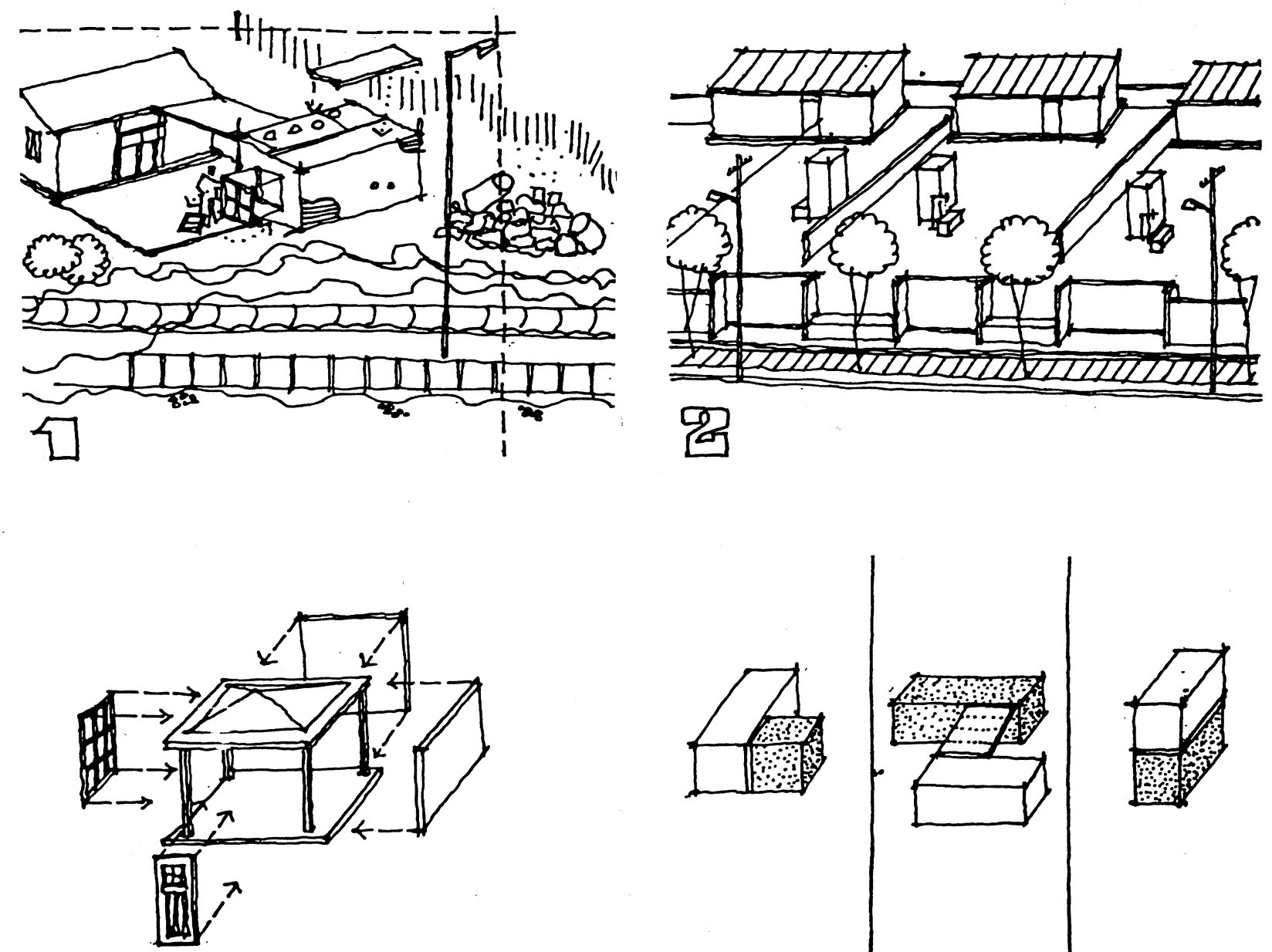

㽞

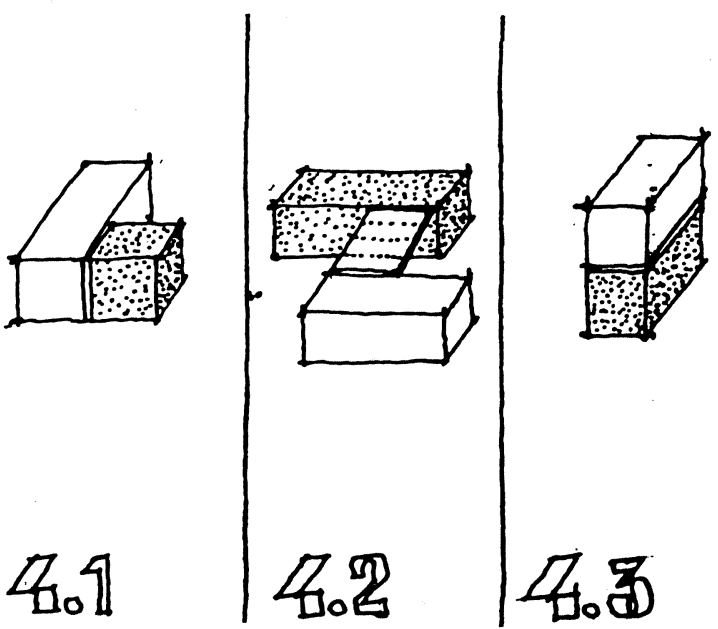




\section{ejemplo 1}

Obra La Merced

Autor: ASOCIACION DE VIVIENDA ECONOMICA (AVE)

Este es un programa típico de rehabilitación de un asentamiento. La Institución AVE, en un trabajo conjunto con la comunidad, analiza las necesidades prioritarias, y les brinda asistencia técnica para apoyar sus soluciones. Así, a nivel urbano es el ordenamiento geométrico y legalización de la tierra, la red de agua potable y la ejecución de salones comunitarios. A nivel individual, el apoyo técnico está centrado en la mejora del hábitat existente. Desde el diseño de las ampliaciones, hasta el mejoramiento y/o reemplazo de los componentes en vivienda.

Tecnológicamente, sólo puede decirse que, menos que nunca, hay fórmulas rígidas. La verdadera tarea profesional es el aprovechamiento de los recursos, tan variados como de previsión inestable.

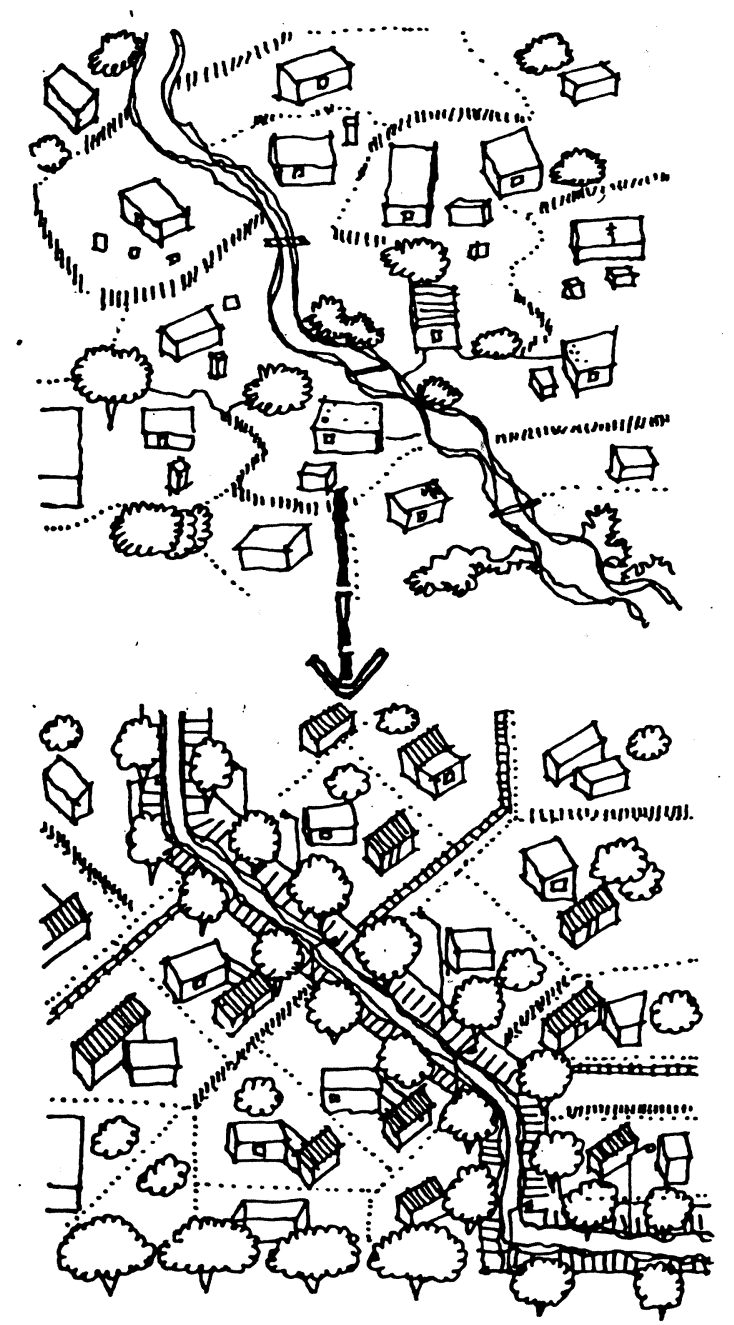

REHHOILACIÓN OE CONJUNO: PARCELAMISHO, IN FRAETRUGTURK. FOUPAMIEMTO COMUNKARIO

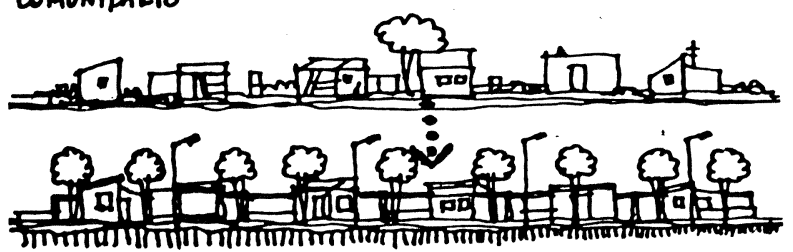

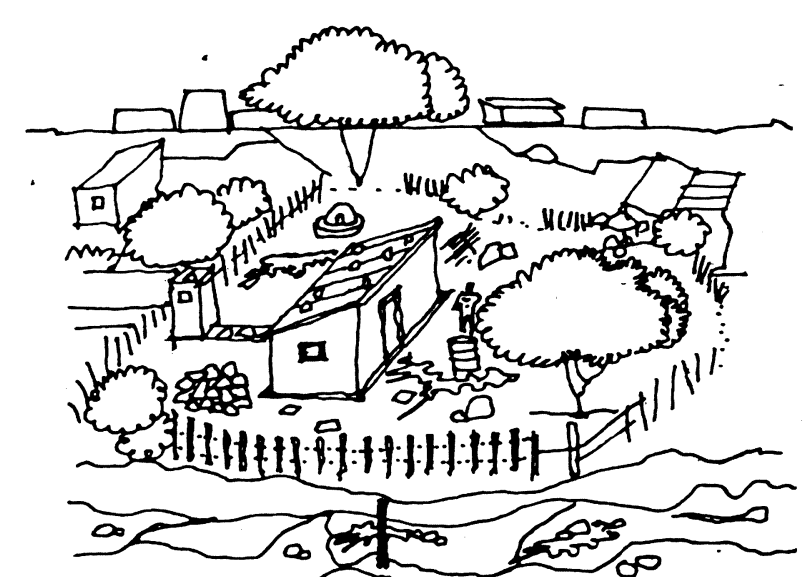

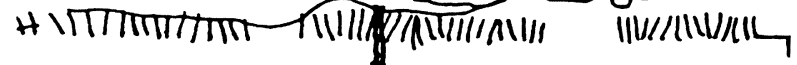

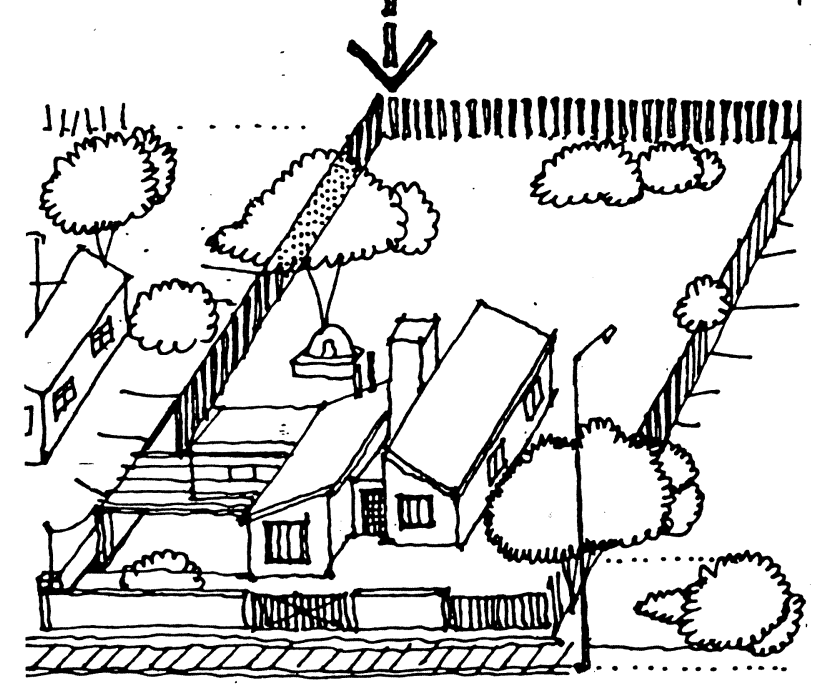

REHAGIHTACION DE LE CELLLA HABKACIONAL EN LOS ASPECTOS DE OISÉNO Y RECNOLOGIN

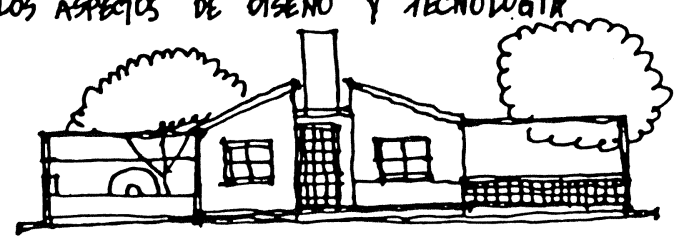




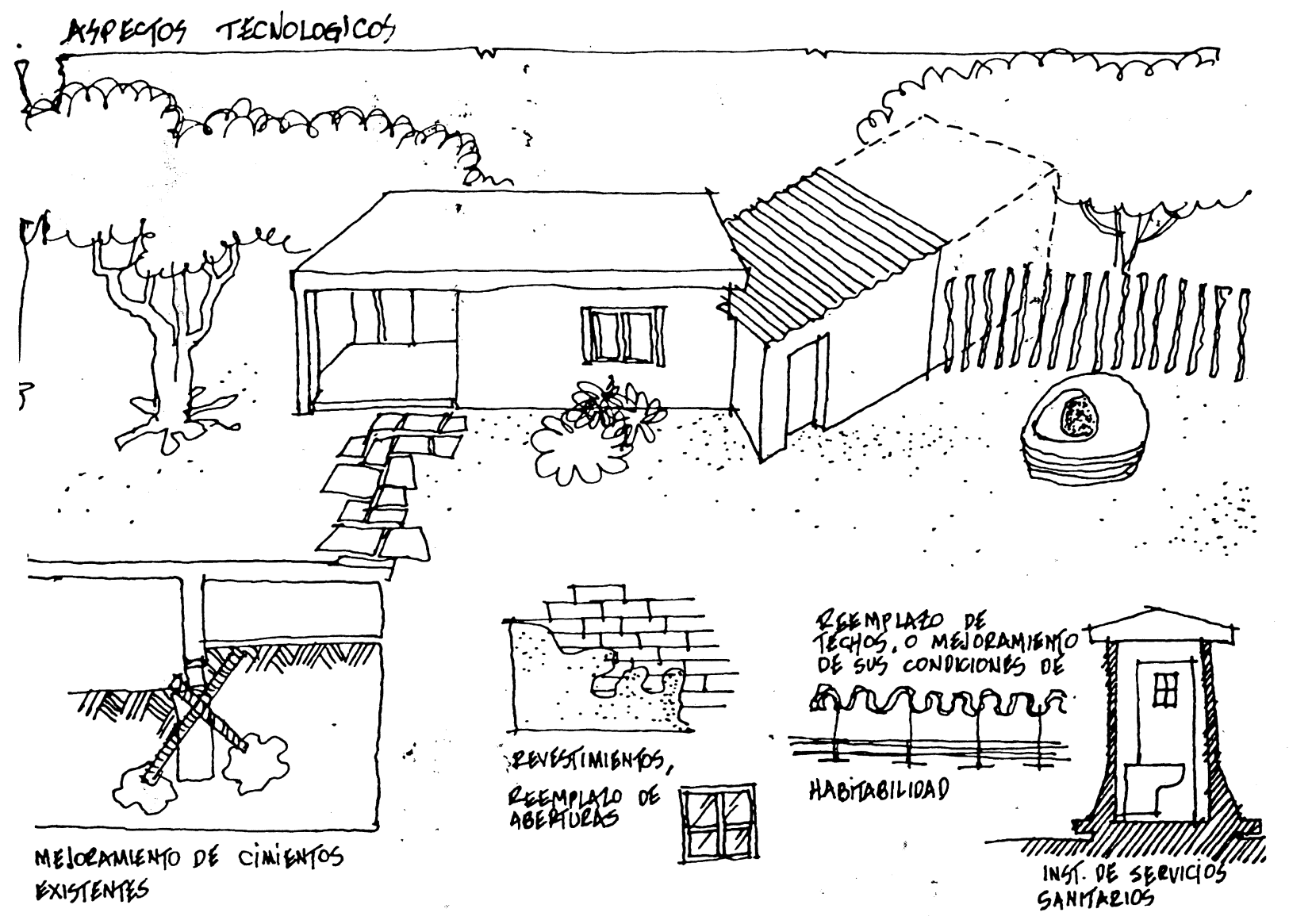

\section{ejemplo 2}

Obra Plan Las Flores I

Autor: ASOCIACIONES DE VIVIENDA ECONOMICA (AVE)

Este programa fue llevado a cabo en Córdoba, por una institución privada dedicada a ejecutar programas de vivienda y promoción social. Consiste en la entrega de un sitio con servicios de infraestructura, el que se complementa con una estructura de "prefachada". Se trata de elementos que definen un limite entre el espacio público y el privado, conformando un perfil urbano para el conjunto incipiente. El grupo realiza estas obras por el sistema de ayuda mutua, iniciando asi un proceso de participación y organización comunitaria. Posteriormente, y en un plazo determinado, las familias se trasladan a la construcción definitiva que realicen, o a fondo de lote en construcción provisoria. Desde alli se construye lo que será la vivienda definitiva, y en forma progresiva también, acorde a los recursos.

Aquí, el aspecto tecnológico es bastante libre respecto a la vivienda, y más bien a través de la asistencia técnica se asegura la calidad de la construcción. En cambio, en la vivienda provisoria, el requerimiento tecnológico puede ser la rapidez del montaje, o la recuperabilidad de los componentes. 

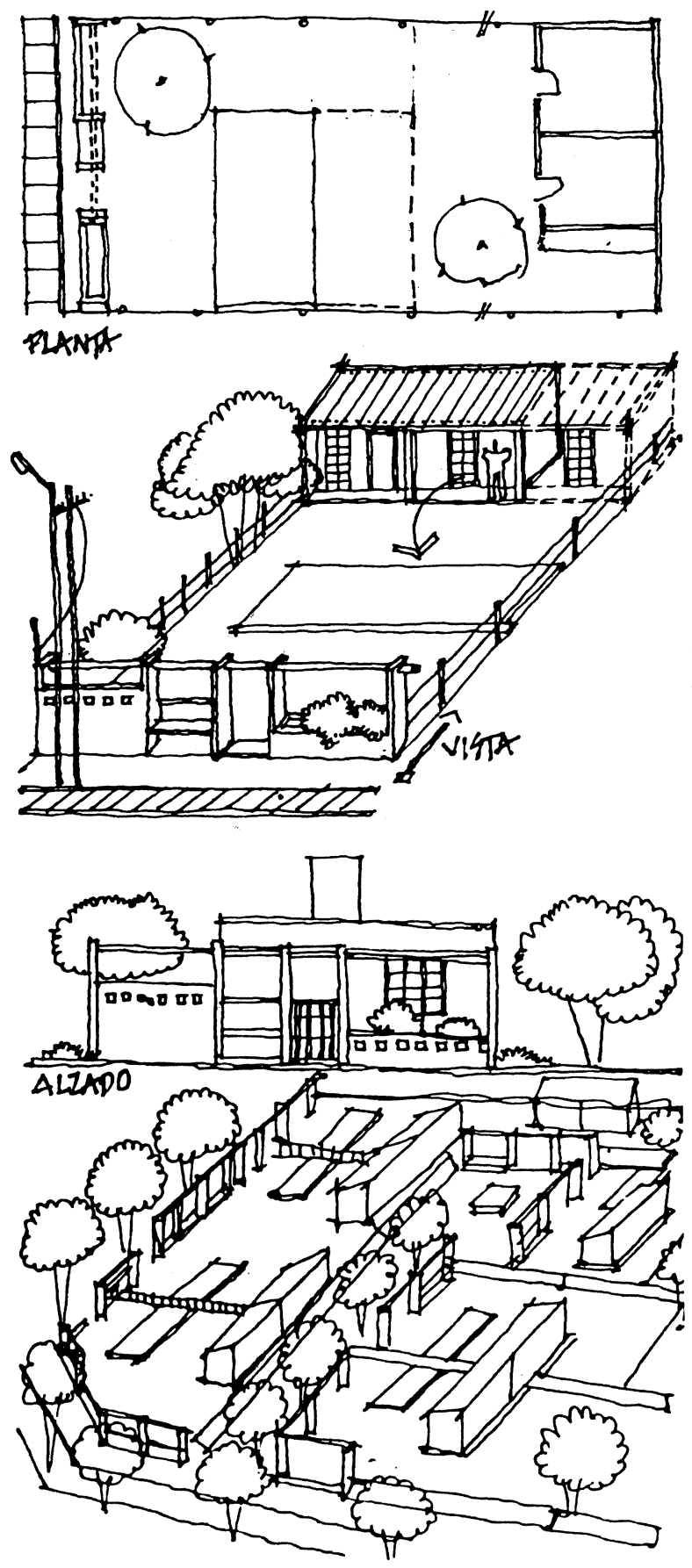

OTRKS DEKS DE PROGRANAS SIMILARES
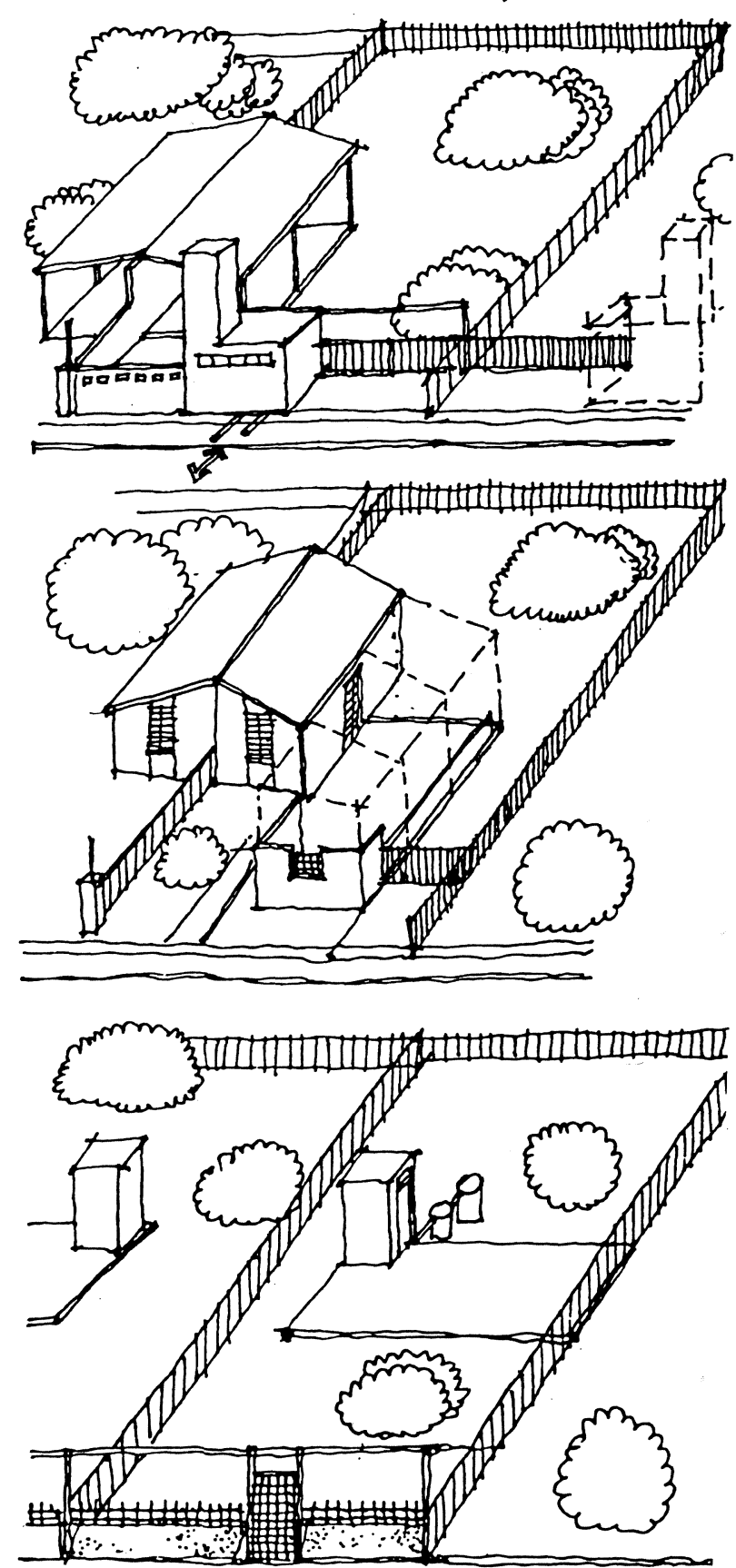


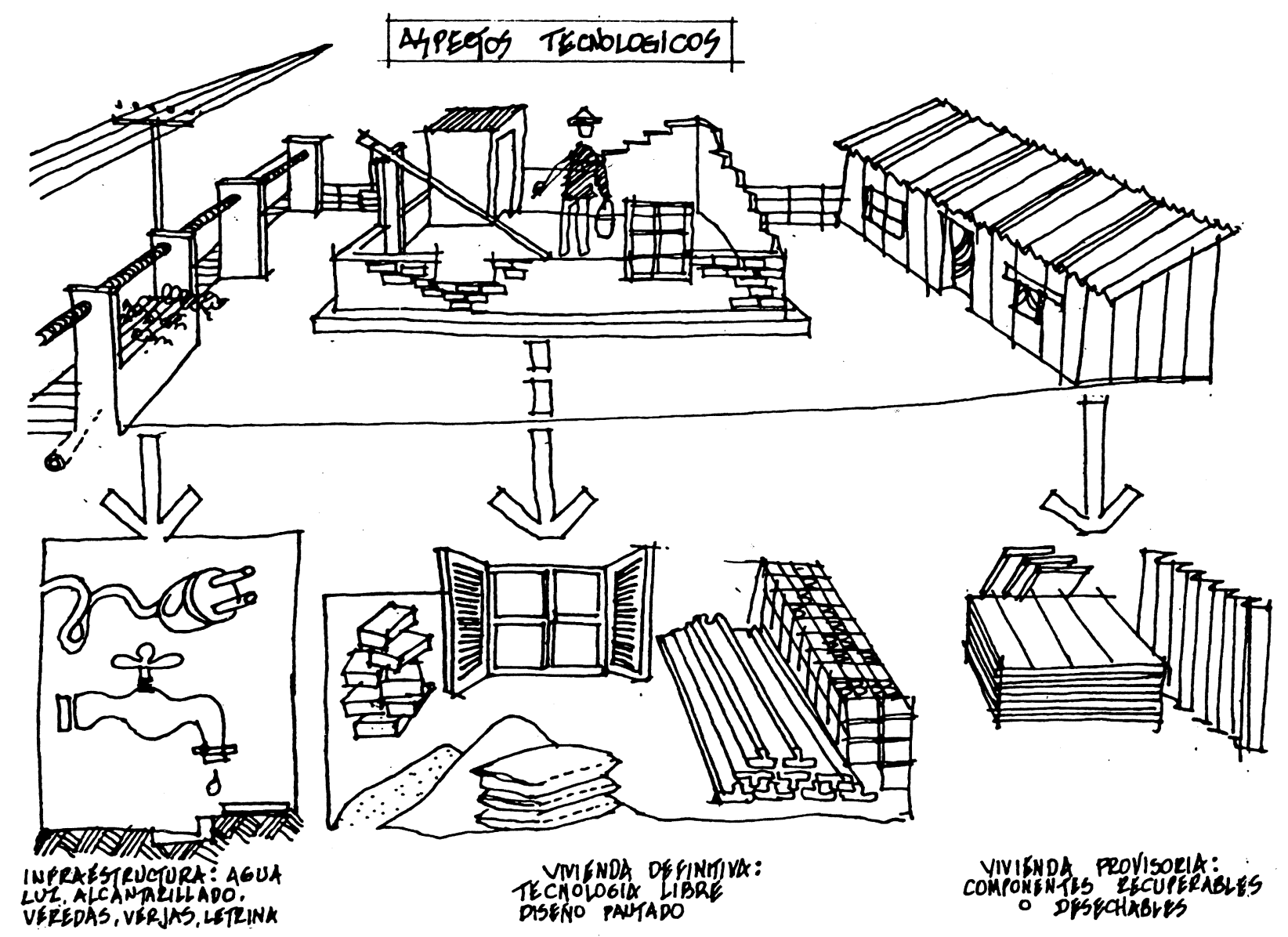

\section{ejemplo 3}

Obra Conjunto Santa Catalina, Chaco Autor: UNNE-UNO. Arq. Victor Pelli

Se entrega al usuario elementos de conjunto que escapen a sus posibilidades individuales de solución. El usuario pasa a habitar un "techo" de inmediato, para encarar por su cuenta los elementos de cierre (envolventes verticales) y terminaciones. Esta diferenciación permite aplicar tecnologias altamente industrializadas en primera etapa (velocidad, economia, seriado) y resolver por otro lado, con técnicas artesanales, el resto, luego de la toma de posesión de la vivienda.
La propuesta constituia un sistema confortable en cada caso de aplicación. Esto implica un sistema abierto que, manteniendo sus pautas básicas, provea distintas alternativas tanto para la definición de la unidad (cantidad de módulos) como para el diseño del conjunto.

Las soluciones tecnológicas, las formas de participación deben definirse en una etapa técnica de ajuste de la propuesta en cada aplicación.

Se permuta, en sintesis, el concepto uentregar vivienda" por "entrega de un sistema de solución a los obstáculos insalvables". 


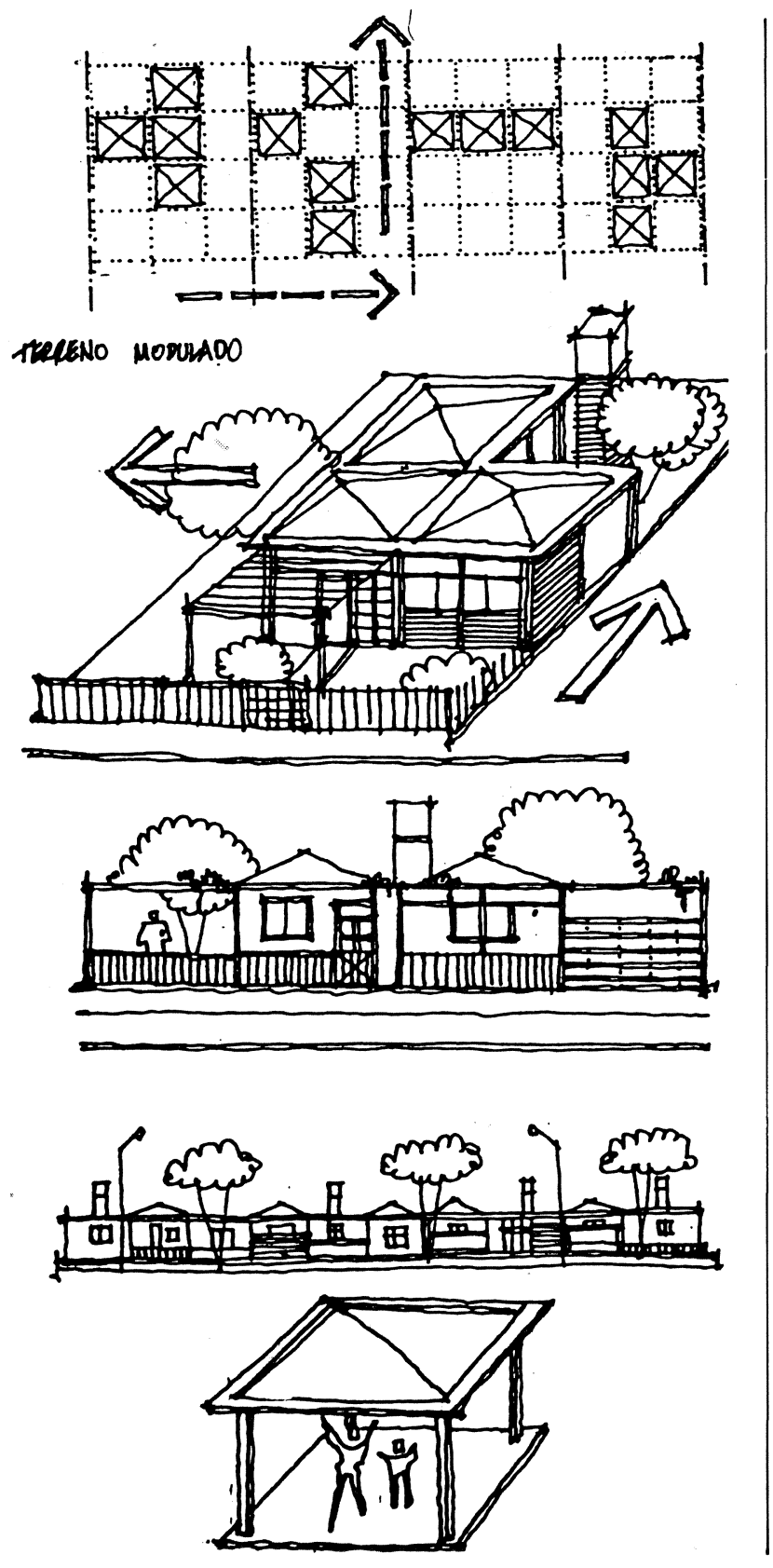

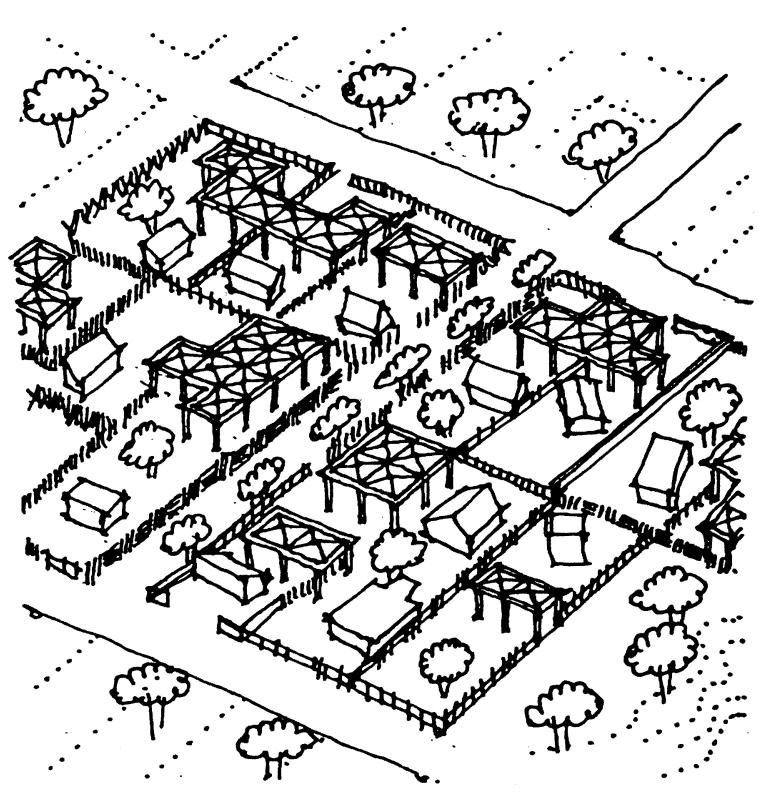

VISTK AEREA
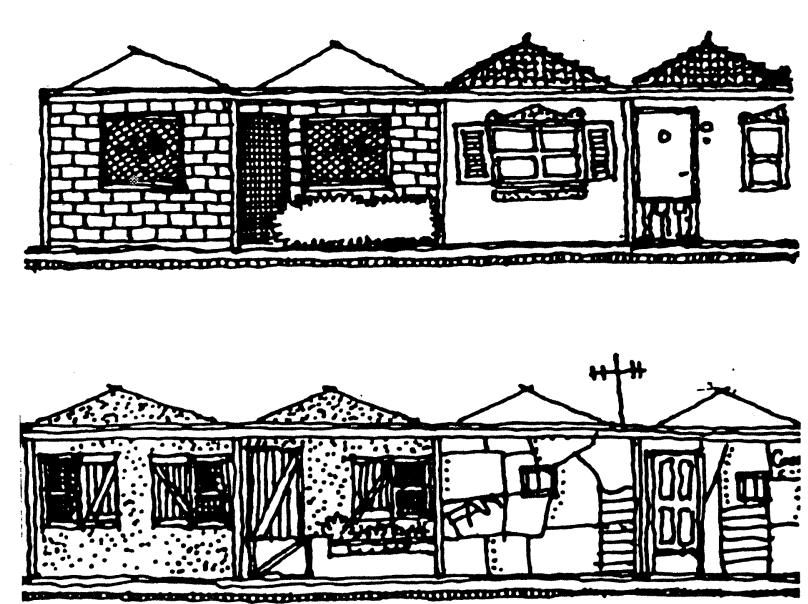

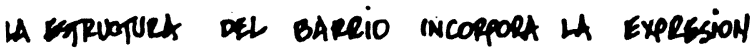
JNONIOUAL 


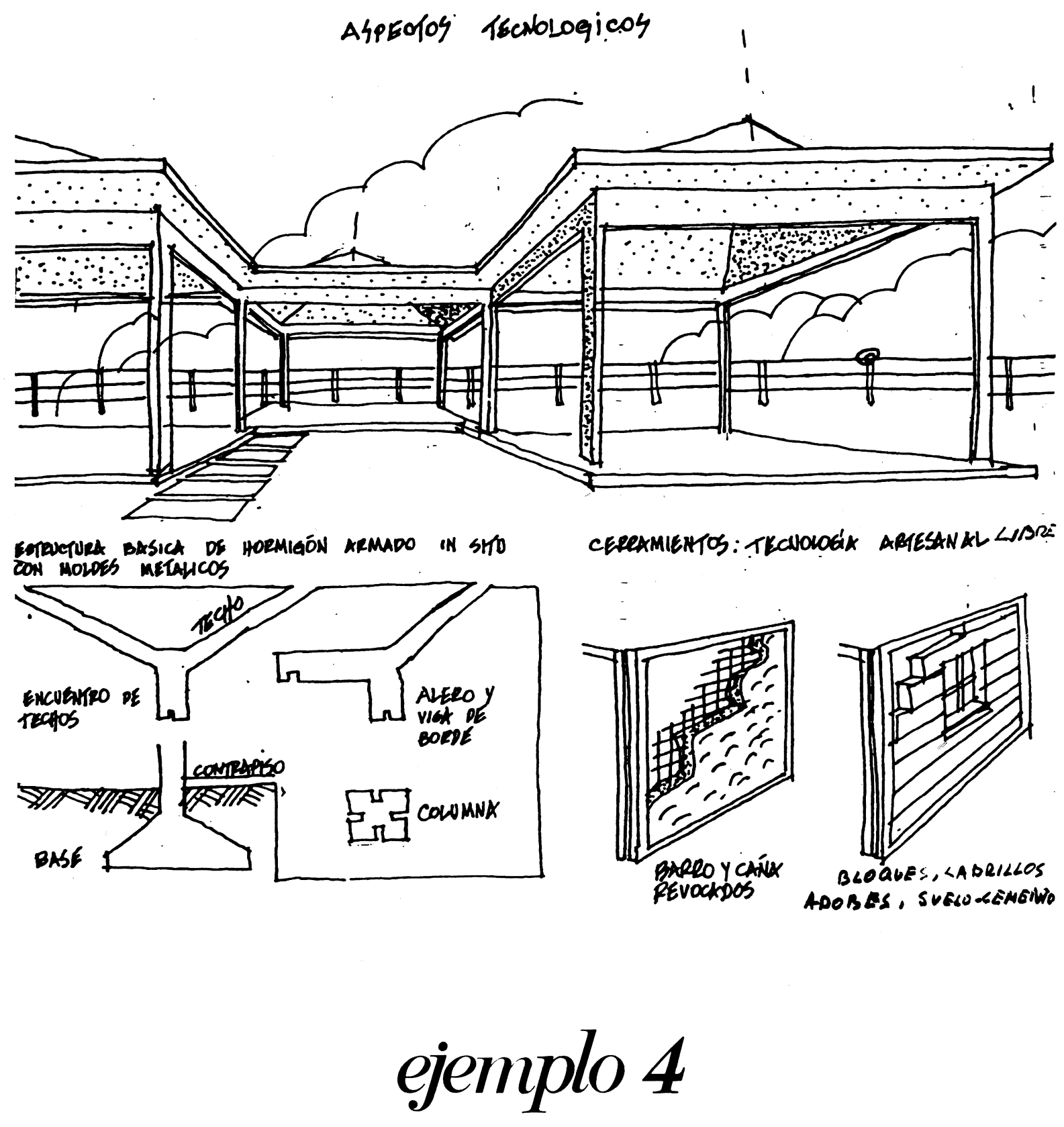

Prototipo Obra Social Sindicato Petrolero de Córdoba

Autor: Arq. Aurelio Ferrero

Se trata de un prototipo de vivienda para sectores obreros, de radicación en áreas periurbanas. La entidad patrocinante otorga el asesoramiento profesional y la venta de materiales al costo, como un servicio. El diseño, compacto (mononuclear) es un rectángulo de $40 \mathrm{~m}^{2}$ de superficie que tiene cocina-comedor-baño y un dormitorio. Su modulación admite tres alternativas tecnológicas en los muros, en base a un módulo básico de $40 \mathrm{~cm}$. La idea es crear un diseño suficientemente versátil para adaptarse a distintos componentes. El techo, también es de una única luz, y es posible resolverlo con diversos tipos estructurales (aun para las ampliaciones). También las aberturas, se resuelven a partir de dos perfiles básicos. Con el mismo criterio, esta célula básica admite distintas posiciones dentro de un lote (básicamente el de $10 \times 25$ en Argentina).

Se trata, en sintesis, de llegar al "mono-elementon: es decir, la menor cantidad posible de elementos distintos con la máxima combinabilidad.

El prototipo fotografiado tiene fundación por platea, muros de bloques de concreto y techo nervurado de hormigón armado. 
DISTNAAY. ALERAATIVAY DE

UGICACION EN EL LOTE
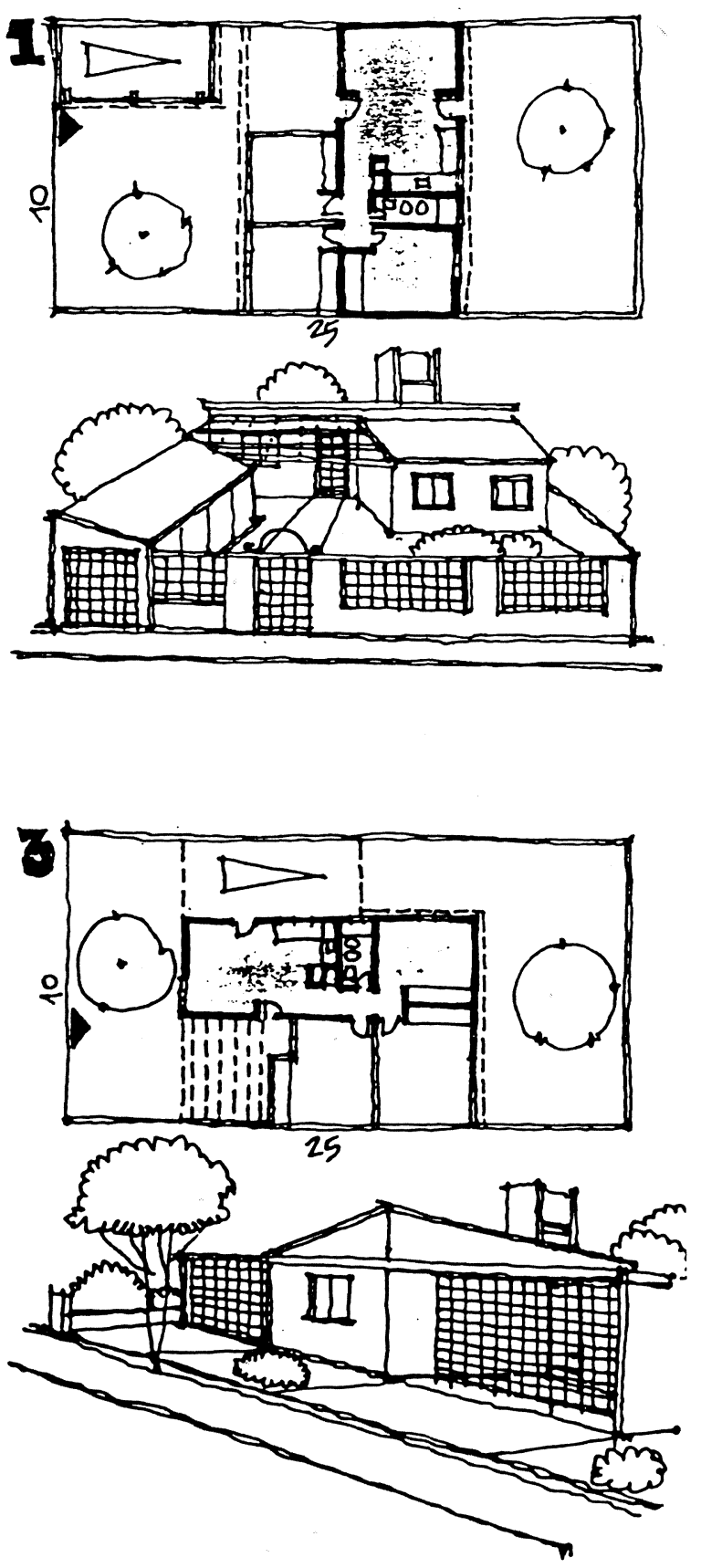
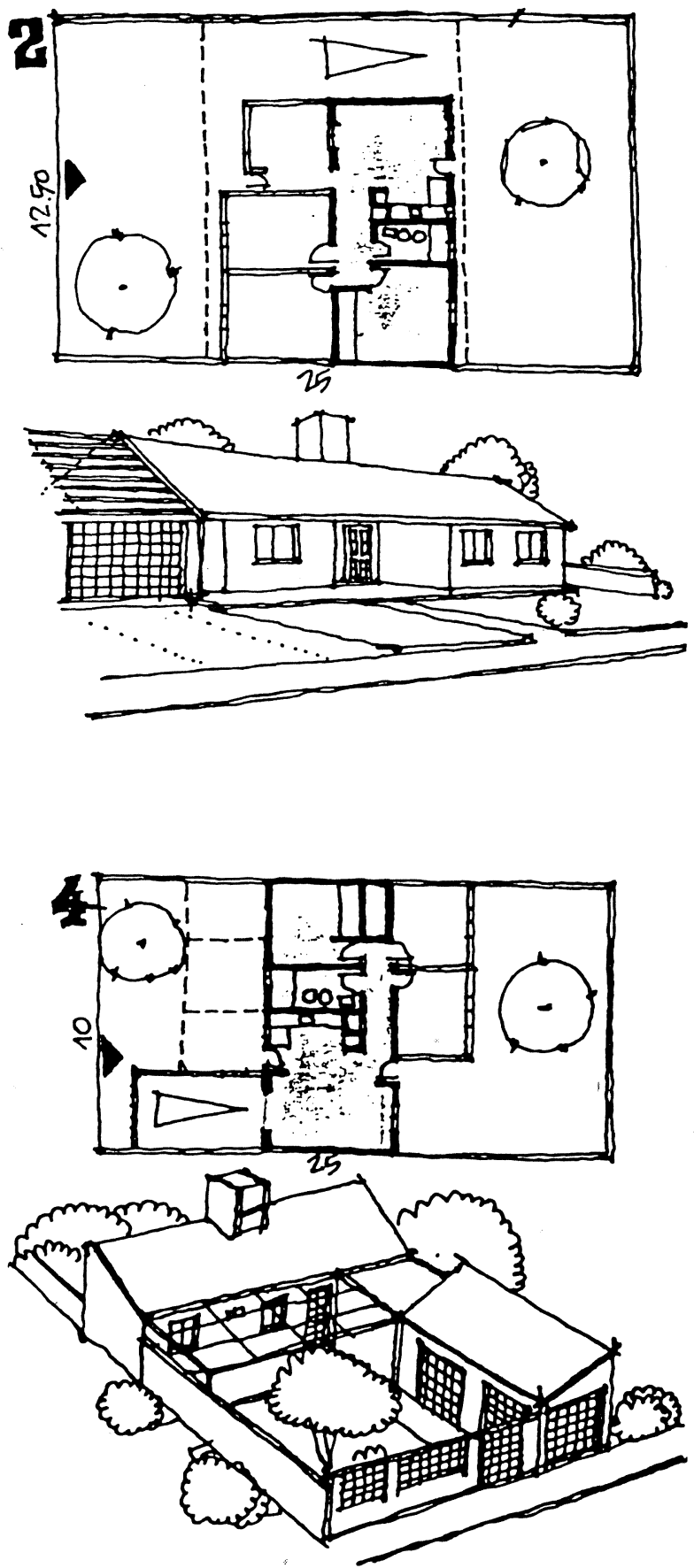

http://informesdelaconstruccion.revistas.csic.es 


\section{LTERNATIVAS TECNOLOGICAS}

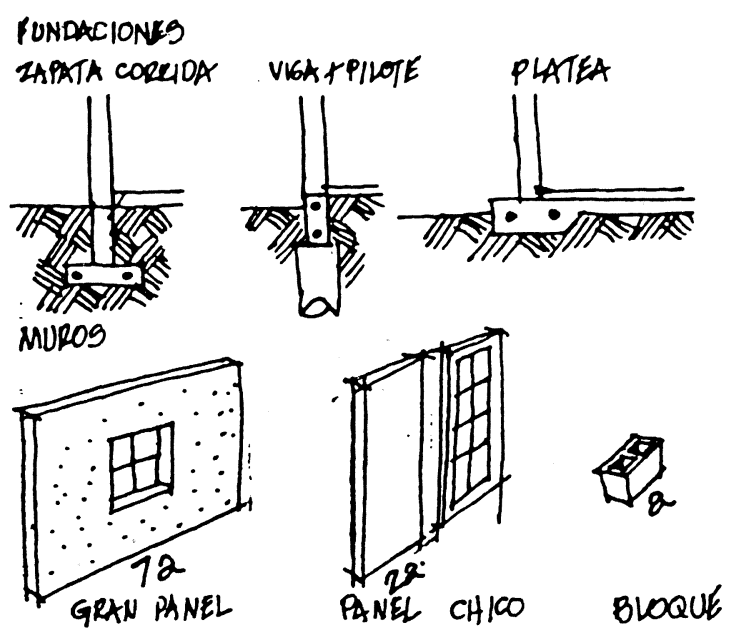

TECHOS
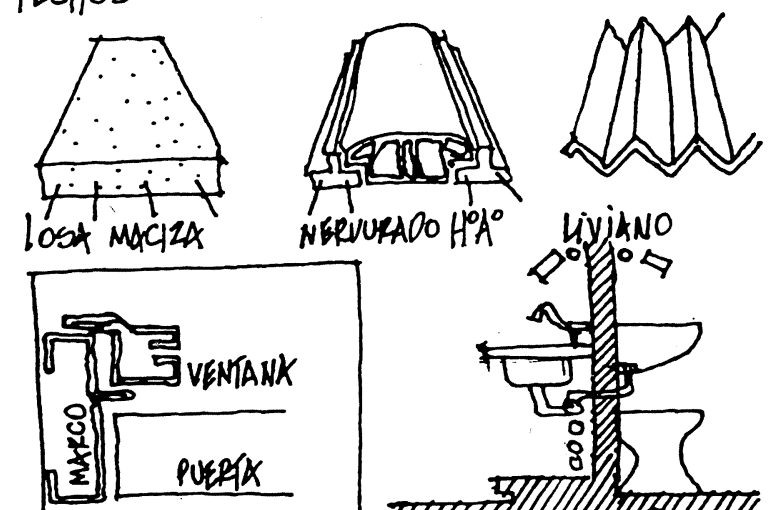

ABERTURAS

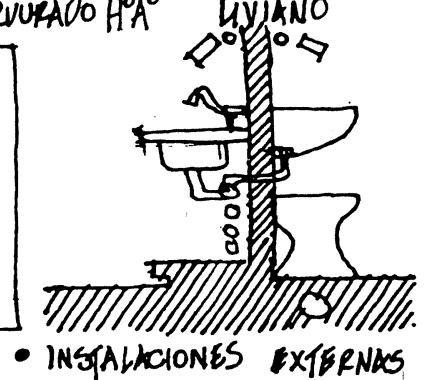

\section{CONCLUSIONES}

La variedad de situaciones, por lo extenso y heterogéneo de la región y por la diversidad de casos existentes, aun dentro de cada pais, aconseja pensar en distintos problemas y, en consecuencia, en que los modos de enfrentarlos se multiplican. No hay una solución actual al problema de la vivienda en Iberoamérica; puede haber tantas soluciones como problemas (o aun más soluciones que problemas). Al introducirnos en el tema, es necesario pensar en plural.

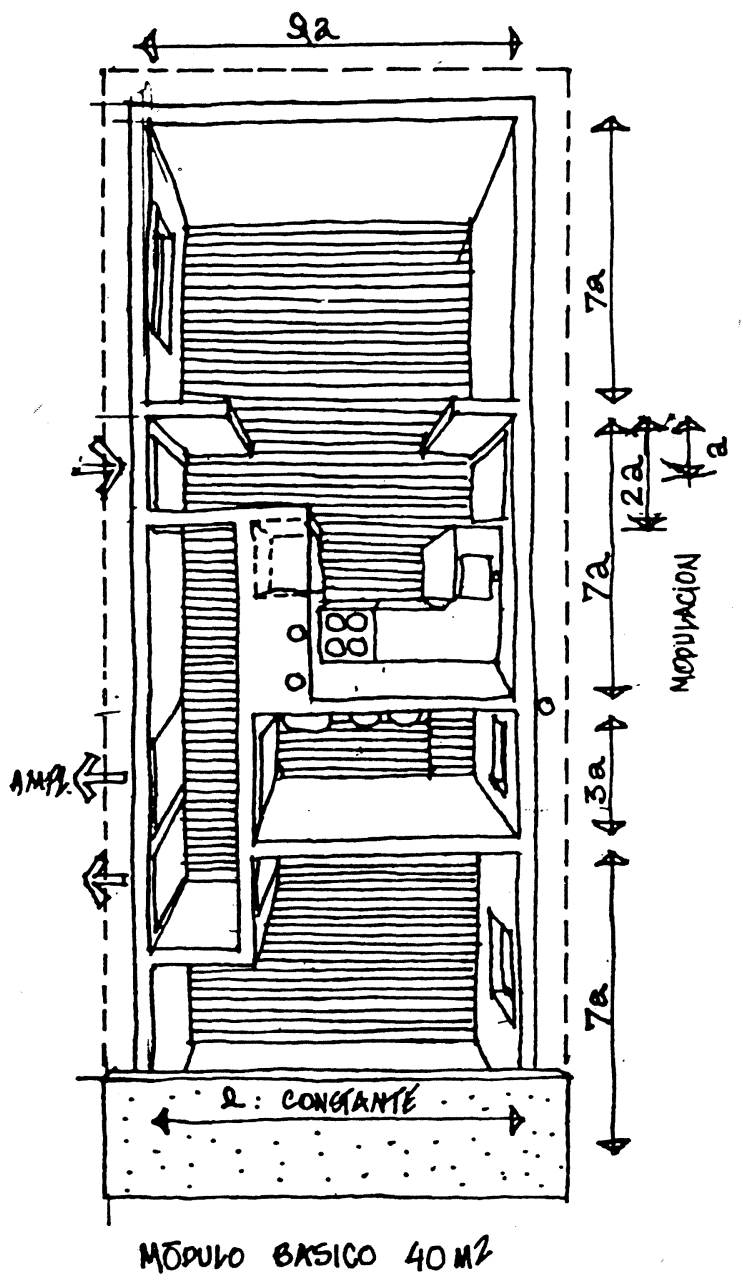

Asi dejamos aclarado que la que presentamos es solamente otra alternativa, una más entre las muchas posibles.

Bibliografia:

- Pelli, Victor S., Matta de Moreschi, Susana; 1979; "Consolidación de barrios marginales"; Facultad de Arquitectura y Urbanismo UNNE, Argentina.

- Centro Experimental de la Vivienda Económica; 1983; "La vivienda adecuadan; Asociación de Vivienda Económica, Argentina.

- Centro Experimental de la Vivienda Económica; 1982; "Estructura de costos en la construcción de viviendas; Vivienda autopromovidan; Subsecretaria de Ciencia y Tecnologia, Argentina. 